\title{
Pulmonary Rehabilitation After Lobectomy On Pulmonary Aspergilloma: Case Report
}

\section{Andwi Setiawan Kokok, Selly Christina Anggoro, Siti Chandra Widjanantie}

Department of Physical Medicine and Rehabilitation, Faculty of Medicine University of Indonesia/Dr. Cipto Mangunkusumo Hospital, Jakarta, Indonesia

Department of Physical Medicine and Rehabilitation, Persahabatan Hospital, Jakarta, Indonesia

\begin{abstract}
Introduction: Complete resection of aspergilloma in chronic pulmonary aspergillosis (CPA), may has several health problem after surgery berupa sesak napas, batuk yang tidak efektif.

Methods: A case presentation of 45 years old woman, after lobectomy on right upper of lung due to aspergilloma, with history of cough and haemoptysis for 3 months. Pulmonary Rehabilitation were breathing retraining exercise (BE), mobilization technique (MT), chest mobility exercise (CM), active cycle breathing technique (ACBT), postural correction exercise (PC) for three weeks.

Results: There were dyspnea, peak flow rate (PFR:60-70-60), peak cough flow (PCF: 70-90-60 L/m), and abnormal chest expansion (CE: $2.5-3-2$ ) $\mathrm{cm}$. After three weeks of Pulmonary Rehabilitation, there were no dyspnea, increased the PCF: $193 \mathrm{~L} / \mathrm{m}$, and CE: 2.5-4-3.

Conclusion: Pulmonary Rehabilitation programs for three weeks were relieved dyspnea, increased cough capacity and CE

Keywords: Aspergilloma, Lobectomy, Bell's Palsy, Rehabilitation program, Cough capacity, Chest expancy
\end{abstract}




\section{ABSTRAK}

Pendahuluan: Reseksi komplet pada aspergilloma paru memiliki masalah kesehatan pascaoperasi berupa sesak napas dan batuk yang tidak efektif.

Metode: Laporan kasus seorang wanita, 45 tahun dengan riwayat lobektomi kanan atas karena aspergilloma yang awalnya datang dengan batuk dan muntah darah selama 3 bulan. Ia diberikan latihan nafas ulang (BE), teknik mobilitasi (MT), latihan mobiltas dada (CM), teknik siklus pernafasan aktif (ABCT), latihan koreksi postural (PC).

Hasil: Ditemukan adanya batuk yang tidak efektif (PCF: 90L/m) dan pengembangan dada abnormal (2.5 - 3 - $2 \mathrm{~cm}$ ). Setelah menjalani program Rehabilitasi Paru selama 3 minggu, tidak ditemukan sesak napas, terdapat peningkatan PCF: $193 \mathrm{~L} / \mathrm{m}$, and CE: 2.5-4-3.

Kesimpulan: Program Rehabilitasi Paru selama 3 minggu memperbaiki sesak napas, meningkatkan kapasitas batuk dan pengembangan dinding dada.

Kata kunci: Aspergilloma, Lobectomy, Bell's Palsy, Program Rehabilitasi Paru, Kapasitas Batuk, Pengembangan Dada.

\section{Correspondent Detail:}

Andwi Setiawan Kokok

Department of Physical Medicine and Rehabilitation, Faculty of Medicine University of Indonesia/

Dr. Cipto Mangunkusumo Hospital, Jakarta, Indonesia

\section{INTRODUCTION}

According to the WHO report in 2011, around 1.2 million people in the world have been estimated to have chronic pulmonary aspergillosis (CPA) as a sequel to tuberculosis (TB) and most cases occur in South-East Asia, Western Pacific and African regions. ${ }^{1}$ Pulmonary aspergilloma may present as simple aspergilloma (SA) or complex aspergilloma (CA) depending on the thickness of the wall of the cavity and presence or absence of the disease in the surrounding lung, pleura and rest of the lung. Haemoptysis is one of most common symptoms ranging from minor to lifethreatening episodes. The use of antifungal agents, whether systemic or intracavitary, has shown little success in "curing" aspergilloma. Furthermore, these drugs rarely achieve the minimal inhibitory concentrations within the lung cavities. Complete resection of aspergilloma with clear margins offers the most consistent chance of cure. However, the mortality and morbidity reported with surgery has deterred treating physicians from utilizing the surgical option. ${ }^{2}$

Aspergilloma (fungus ball), one of the clinical forms of aspergillosis, develops primarily in 
post-tuberculous cavities and may constitute a significant therapeutic problem due to recurrent haemoptysis and symptoms of chronic infection. Antifungal agent penetration into the cavity of the fungus ball is scant; therefore, in many cases, the only treatment option is to resect the pulmonary parenchyma colonized by the fungus. Notwithstanding, surgical treatment is associated with many technical difficulties and a relatively high risk of postoperative complications, particularly in patients who are emaciated or treated with immunosuppression.

Bell's palsy is an acute idiopathic facial nerve paralysis of sudden onset. It is the most common cause of lower motor neuron facial nerve paralysis with an annual incidence of 15-30 per $100,000 .^{2}$ The pathogenesis of Bell's palsy is presented as retrograde epineurial compression edema with ischemia of the facial nerve. ${ }^{3}$ Bell's palsy is thought to result from compression of the seventh cranial nerve at the geniculate ganglion. The first portion of the facial canal, the labyrinthine segment is the narrowest and it is here that most cases of compression occur. Due to the narrow opening of the facial canal, inflammation causes compression and ischemia of the nerve. The most common finding is a unilateral facial weakness that includes the muscles of the forehead. ${ }^{4}$

The main presenting problems of postoperative patients who have undergone thoracic surgery include improper patient positioning; incision and/or chest drain pain; ineffective cough; reduced lung volume; postoperative pulmonary complications (PPCs), which can be noninfectious (e.g., atelectasis and respiratory failure) or infectious (e.g., pneumonia); impaired airway clearance; frozen shoulder on the thoracotomy side; postural abnormalities; and persistent chest wall tightness. These problems, particularly PPCs, can lead to delayed patient recovery, prolonged hospitalization, and increased morbidity and mortality. Physical rehabilitation and medicine (PMR) has been routinely implemented after thoracic surgery as a fundamental component of postoperative management. Recently, PMR has been recommended by the European Society of Thoracic Surgeons, the European Respiratory Society, and the American College of Chest Physicians, and it is now considered an essential element of enhanced recovery protocols (ERPs) or "fast-track" protocols in thoracic surgery that accelerate the functional recovery of postoperative patients and minimize the length of the hospital stay. Therefore, the role of PMR in these "fasttrack" protocols after thoracic surgery warrants further clarification. ${ }^{5}$

Early mobilization is considered an important element of postoperative care. Mayor et al. did a study implementing thoracic enhanced recovery with ambulation after surgery program and found that the median length of stay was 1 day compared to 2 days before implementation $(\mathrm{P}<0.001)$. Pneumonia rates were also significantly reduced from $6 \%$ to $0.7 \%{ }^{6}$ Castellino et al. did a Systematic Review and Meta-Analysis for early mobilization in patient post thoracotomy and found that although bed rest is harmful, there is little available evidence to guide clinicians in effective early mobilization protocols that increase mobilization and improve outcomes. ${ }^{7}$ 
The central aim for respiratory rehabilitation is to optimize ventilation and clear airway secretions in order to improve gas exchange and make breathing easier. One of the techniques that can iincreases lung volumes is deep breathing exercises with or without devices (e.g. incentive spirometry). Breathing techniques may improve respiratory function postoperatively by increasing functional residual capacity (FRC) and ventilation, and by minimizing closing volumes. ${ }^{8-13}$

\section{CASE PRESENTATION}

A 45-year-old woman presented with chief complaint of productive cough and haemoptysis for 3 months. She denied fever, chills, night sweats, shortness of breath, chest pain and any other symptom. She had a history of pulmonary TB at age 42 . She has no prior diabetes mellitus and never smoked. After surgery, she complained about her inability to cough sputum and pain at post-surgical wound. The intensity of post-surgical wound pain was $2-3$, which minimally pain by visual analogue scale (VAS). There was a hypertensive (150/90 $\mathrm{mmHg}$ ), dyspnea that appearance by use of accessories breathing muscles (upper trapezius, scalenes, sternocleidomastoid, and pectoralis), decreased breath sound and crackles at right hemithorax scattered on right lung, and decreased chest expansion $(2.5-3-2 \mathrm{~cm})$.

Patient condition after surgery were still had central venous catheter (CVC), given oxygen supplementation via nasal canula, and underweight (body mass index was 16.6). She had weak cough and had low peak flow rate (PFR: $60-70-60 \mathrm{~L} / \mathrm{m}$ ), as well as peak cough flow (PCF: $70-90-60 \mathrm{~L} / \mathrm{m}$ ).

\section{Laboratory}

Laboratory results showed low albumin level (2.3 g/dL), mild hyponatremia (133 mEq/L), mild hypokalemia $(3.2 \mathrm{mEq} / \mathrm{L})$, mild anemia $(11.4 \mathrm{~g} / \mathrm{dL})$, increased leukocyte $(21.600 / \mu \mathrm{L})$, but otherwise normal. Acid-fast bacillus (AFB) smear and culture were negative on three sputum samples. HIV test was also negative.

\section{Imaging}

CT of the chest revealed cavity with halo sign and surrounded by fibroinfiltrate in the upper lobe of the right lung (S1 and S2).

\section{Management}

After surgery patient had Fluconazole, B12 vitamin supplementation, Ampicillin Sulbactam for antibiotics, N-acetylcystein (NAC), methylprednisolone for cough, and ketorolac for pain management. Pulmonary Rehabilitation program were breathing retraining exercise (BE) using deep breathing technique without mechanical devices 5 times/ hour, early mobilization (EM) by walking at ward's alley 10 minutes, twice/day, chest mobility exercise (CM) by physiotherapist once daily, active cycle breathing technique (ACBT) was taught to be used when she cough, postural correction exercise (PC) by physiotherapist once daily.

She was a mother with 3 children, that lived at her mother's house together with 8 peoples in the house, so education about to let sunlight in into the house to reduce humidity and reduce fungal overgrowt. Follow up would be done after discharge to measure cough capacity and chest expansion on this patient. Functional outcome such as 6 minutes-walk test, sit-tostand test, and Time Up and Go test (TUG) test would be measured. 


\section{Outcome and Follow-Up}

At 2 days follow up, she reported that she is able to cough more easily and able to stand up. During observation, she was still unable to breathe easily, and she still uses accessories inspiratory muscles. During mobilization challenge she is able to sit independently without any difficulty and increased heart rate (resting HR $100 \mathrm{bpm}$ ), but when she was asked to stand up, she experienced increased heart rate to $115 \mathrm{bpm}$, even though she did not experience any dizziness or other symptoms. She was also able to stand without any balance disorders, she is able to walk several steps. We also notice improvement in her facial expression with less dropped eye and mouth (House Brackmann III). She was not given any analgesic anymore and she rated her postsurgical wound pain with VAS $1-2$. She was then prescribed out of bed mobilization (around her bed) with supervision and was asked to do exercise at our outpatient clinic. She was also scheduled for 6-minute walk test to measure her cardiovascular capacity, PFR and PCF measurement to measure coughing capability. We then decided that the discharge planning of this patient is to be able to ambulate safely around $20-30$ meters, with rate of perceived exertion (RPE) no more than 11, and able to cough sufficiently (PCF: more than $160 \mathrm{~L} / \mathrm{m}$ ). The patient should meet the requirements and able to perform all of the exercises prior to discharge. Outpatient pulmonary rehabilitation program should also be set up before discharge.

During 3 weeks follow up, she already able to walk independently without walking aid. She is able to walk without dyspnea around 300 meters (Borg scale $11-0-0)$. She was able to do more effective cough, increase cough capacity PCF: $193 \mathrm{~L} / \mathrm{m}$, and chest expansion $2.5-4-3 \mathrm{~cm}$.

\section{DISCUSSION}

This case highlights the challenge of establishing a diagnosis of pulmonary aspergilloma. On admission, the main differential diagnoses were pulmonary TB, tuberculoma, aspergilloma, and malignancy. The fact that the patient had a history of pulmonary TB made the diagnosis more challenging because both disorders, TB and aspergillosis, have very similar presentations and can even coexist. In this case during chest $\mathrm{CT}$, it was revealed that she had pulmonary mycosis at S1 and S2 segment of upper lobe of the right lung. This case also emphasizes the importance of differential diagnosis of aspergilloma in patient who presents with haemoptysis. This in in accordance with two recent case report by Ding, et. al. ${ }^{11}$ and Betancourt, et. al. ${ }^{4}$ which also reported that patient with aspergilloma presenting with haemoptysis as its chief complaint.

Unfortunately, we have no data regarding her lung condition before aspergilloma infection. but according to literature, tuberculous cavity may predispose aspergilloma to grow. She also went through 3 months anti-fungal therapy and did not experienced improvement. She was then decided to have lobectomy of the upper lobe of her right lung.

As described at the literature review, post thoracotomy has several problems which presents in this patient such as improper patient positioning, incision and/or chest 
drain pain, ineffective cough, reduced lung volume, infectious postoperative pulmonary complications (PPCs), impaired airway clearance, and postural abnormalities. Pain management is crucial in post thoracotomy rehabilitation, to correct postural abnormalities, prevent frozen shoulder, and optimal chest expansion. Deep, segmental, and splinting breathing exercise was then prescribed at this patient to reduce pain during breathing and increase chest expansion. ${ }^{5}$ Tactile stimuli, which was conducted via larger nerve fiber $(\mathrm{A} \beta$ fiber), may inhibit pain transmission, which was conducted via smaller nerve fiber (A $\sigma$ and $\mathrm{C}$ fiber). With gentle pressure, it also makes sure that the wound does not move too much, hence, less pain is perceived by the patient. ${ }^{12}$ Once pain has lessen, the patient will be able to breathe deeper (to allow cough) and more easily, therefore preventing accessories inspiratory muscle use. Less muscle use to breathe results in less effort and therefore making the patient able to do activity of daily living (ADL) more independently (without dyspnea). Other than $\mathrm{BE}$, the patient was also prescribed $\mathrm{CM}$ to prevent frozen shoulder, postural correction, and further increasing chest expansion. In order to have sufficient cough capacity to expel sputum, the patient need to have better chest expansion and tidal volume. This finding is in according to previous study by Woo et. al. that the breathing with mainly inspiration group (BMIG) showed significant differences in chest size during inspiration (CSI), chest expansion values (CEVs), forced vital capacity (FVC), forced expiratory volume in one second (FEV1), and peak expiratory flow (PEF) after four weeks. ${ }^{12}$

We also taught the patient to do ACBT in order to expel sputum with less effort. During 2 days follow up, we found $\mathrm{CVC}$ was remain attached. We suspect that this may cause leucocytosis in this patient $(21.600 / \mu \mathrm{L})$, and therefore suggest that the CVC to be removed had it was not used anymore. Mobilization technique was also introduced to this patient to further increasing cough capacity. Active mobilization has been linked with better sputum expulsion. ${ }^{13}$

There were several limitations at the rehabilitation management, such as prescription of inspiratory muscle trainer (IMT) or incentive spirometry, as a major component of preoperative pulmonary rehabilitation programs. A recent study by Brocki et al. has shown that the addition of IMT to standard breathing exercise improved hypoxaemic status in high-risk patients after lung cancer surgery. Due to economic issues of this patient and BPJS insurance does not cover the prescription of IMT, therefore we did not prescribe IMT for this patient. Another limitation is unclear follow up. Since this case report only describe present condition.

\section{CONCLUSION}

Pulmonary Rehabilitation after lobectomy on aspergilloma, included $\mathrm{BE}, \mathrm{MT}, \mathrm{CM}, \mathrm{ACBT}$, and PC for three weeks improved cough capacity and chest expansion, after all relieved dyspnea.

\section{REFERENCES}

1. Moodley L, Pillay J, Dheda K. Aspergilloma and the surgeon. J Thorac Dis. 2014; 6(3): 202-9. doi: 10.3978/j. issn.2072-1439.2013.12.40 
2. Hayes GE, Novak-Frazer L. Chronic Pulmonary Aspergillosis-Where Are We? and Where Are We Going? J Fungi (Basel). 2016; 7;2(2). pii: E18. doi: 10.3390/jof2020018.

3. Kaspryzk M, Pieczynski K, Mania K, Gabryel P, Piwkowski C, Dyszkiewicz W. Surgical treatment for pulmonary aspergilloma - early and long-term results. Kardiochir Torakochirurgia Pol. 2017;14(2):99-103. doi: 10.5114/ kitp.2017.68738.

4. Kanj A, Abdallah N, Soubani AO. The spectrum of pulmonary aspergillosis. Respir Med. 2018;141:121-131. doi: 10.1016/j.rmed.2018.06.029. Epub 2018 Jul 3 .

5. Iqbal N, Irfan M, Zubairi ABS, Jabeen K, Awan S, Khan JA. Clinical manifestations and outcomes of pulmonary aspergillosis: experience from Pakistan. BMJ Open Respir Res. 2016; 7;2015. pii: bcr2015211249. doi: 10.1136/bcr-2015211249

6. Kumar A, Asaf BB, Puri HV, Lingaraju VC, Siddiqui S, Venkatesh PM, et.al, Video-assisted thoracoscopic surgery for pulmonary aspergilloma. Lung India. 2017;34(4):318-323. doi: 10.4103/09702113.209232 .

7. Ahmad AM. Essentials of Physiotherapy after Thoracic Surgery What Physiotherapists Need to Know. A Narrative Review. Korean J Thorac Cardiovasc Surg. 2018; 51(5): 293-307

8. Mayor MA, Khandhar SJ. Chandy J, Fernando HC. Implementing a thoracic enhanced recovery with ambulation after surgery program: key aspects and challenges. J Thorac Dis. 2018;10(Suppl 32):S3809-S3814. doi: 10.21037/ jtd.2018.10.106.

9. Castelino T, Fiore JF, Niculiseanu P, Landry $\mathrm{T}$, Augustin B, Feldman LS. The effect of early mobilization protocols on postoperative outcomes following abdominal and thoracic surgery: A systematic review. Surgery. 2016;159(4):991-1003. doi: 10.1016/j. surg.2015.11.029.

10. Andersen KS, Skoffer B, Oestergaard LG, Tulder MV, Petersen AK. The effects of respiratory physiotherapy after lung resection: Protocol for a systematic review. IJS Protocols. 2017; 24:1-19. doi: 10.1080/09593985.2018.1564095

11. Ding WY, Chan T, Yadavilli RK, McWilliams R. Aspergilloma and massive haemoptysis. BMJ Case Rep. 2014; 16;2014. pii: ber2013200019. doi: 10.1136/bcr-2013-200019

12. Woo SD, Kim TH, Lim JY. The effects of breathing with mainly inspiration or expiration on pulmonary function and chest expansion. J Phys Ther Sci. 2016; 28(3): 927-931

13. Dwyer TJ, Daviskas E, Zainuldin R, Verschuer J, Eberl S, Bye PTP, et.al. Effects of exercise and airway clearance (positive expiratory pressure) on mucus clearance in cystic fibrosis a randomised crossover trial. Eur Respir J. 2019;18;53(4). pii: 1801793. doi: 10.1183/13993003.017932018. Print 2019 Apr. 